\title{
Efficacy of endoscopic management for anastomotic leakage after gastrectomy in patients with gastric cancer
}

\author{
Young-II Kim ${ }^{1} \cdot$ Jong Yeul Lee ${ }^{1} \cdot$ Harbi Khalayleh ${ }^{1,2} \cdot$ Chan Gyoo Kim$^{1} \cdot$ Hong Man Yoon ${ }^{1} \cdot$ Soo Jin Kim ${ }^{1}$. \\ Hannah Yang ${ }^{1,3} \cdot$ Keun Won Ryu ${ }^{1} \cdot$ II Ju Choi ${ }^{1} \cdot$ Young-Woo Kim ${ }^{1,4}$ (D)
}

Received: 2 February 2021 / Accepted: 2 June 2021 / Published online: 12 July 2021

(C) The Author(s) 2021

\begin{abstract}
Background Anastomotic leakage (AL) after gastrectomy in gastric cancer patients is associated with high mortality rates. Various endoscopic procedures are available to manage this postoperative complication. The aim of study was to evaluate the outcome of two endoscopic modalities, clippings and stents, for the treatment of AL.

Patients and methods There were 4916 gastric cancer patients who underwent gastrectomy between December 2007 and January 2016 at the National Cancer Center, Korea. A total of 115 patients (2.3\%) developed AL. Of these, 85 patients (1.7\%) received endoscopic therapy for AL and were included in this retrospective study. The endpoints were the complete leakage closure rates and risk factors associated with failure of endoscopic therapy.

Results Of the 85 patients, 62 received endoscopic clippings (with or without detachable snares), and 23 received a stent insertion. Overall, the complete leakage closure rate was $80 \%$, and no significant difference was found between the clipping and stent groups $(79.0 \%$ vs. $82.6 \%$, respectively; $P=0.89)$. The complete leakage closure rate was significantly lower in the duodenal and jejunal stump sites $(60 \%)$ than esophageal sites $(86.1 \%)$ and gastric sites $(94.1 \% ; P=0.026)$. The multivariate analysis showed that stump leakage sites (adjusted odds ratio $[\mathrm{aOR}], 4.51 ; P=0.031$ ) and the presence of intra-abdominal abscess (aOR, 4.92; $P=-0.025$ ) were associated with unsuccessful leakage closures.

Conclusions Endoscopic therapy using clippings or stents is an effective method for the postoperative management of AL in gastric cancer patients. This therapy can be considered a primary treatment option due to its demonstrated efficacy, safety, and minimally invasive nature.
\end{abstract}

Keywords Anastomotic leakage $\cdot$ Endoscopic therapy $\cdot$ Gastrectomy

Abbreviations

AL Anastomotic leakage

ASA American Society of Anesthesiologists

Jong Yeul Lee

jylee@ncc.re.kr

$\triangle$ Young-Woo Kim gskim@ncc.re.kr

1 Center for Gastric Cancer, National Cancer Center, 323 Ilsan-ro, Ilsandong-gu, Goyang 10408, Republic of Korea

2 The Department of Surgery, Faculty of Medicine, Kaplan Medical Center, Hebrew University of Jerusalem, Jerusalem, Israel

3 Division of Biology and Biological Engineering, California Institute of Technology Pasadena, Pasadena, CA 91125, USA

4 Department of Cancer Control and Population Health, Graduate School of Cancer Science and Policy, 323 Ilsan-ro, Ilsandong-gu, Goyang 10408, Republic of Korea
IRB Institutional Review Board

CT Computed tomography

SEMS Self-expandable metal stent
The incidence of gastric cancer remains significant in East Asian countries [1], but the mortality is decreasing due to a combination of nationwide gastric cancer screening programs and advancements in radical surgery, technology, and procedural techniques $[2,3]$. However, anastomotic leakage (AL) is an alarming and life-threatening postoperative complication that is significantly associated with postoperative mortality in gastric cancer patients [4]. Approximately, 1.7 to $7.5 \%$ of all complications [5-9] and 20 to $75 \%$ of postgastrectomy mortality (depending on the type of gastrectomy performed) [10-13] is attributed to ALs. Other than mortality, the consequences of AL include reduced digestive 
function and quality of life [14], in addition to increased hospital stay and financial burden $[4,15]$.

There are three therapeutic modalities to treat this condition: surgical reoperation of septic patients with early and acute $\mathrm{AL}$, conservative management of late and asymptomatic AL patients, and endoscopic management for patients with severity between these two ends of the spectrum [16]. Reoperations were previously the method of choice for AL treatment but are associated with high rates of morbidity and mortality [7, 8]. Minimally invasive endoscopic intervention has continually gained evidence-based support [17-21], which has resulted in a paradigm shift toward endoscopic management of ALs in the past 20 years.

Out of the many emerging endoscopic strategies for the management of AL, two accepted and widespread applications are the use of clippings and stents. Favorable outcomes have been reported in serial case studies of patients who received different variations of these two techniques, including endoscopic clippings with or without detachable snares [18, 19], over-the-scope clip systems [20], and self-expanding stents $[17,18,21]$. However, these studies are limited by small case sizes (fewer than 30) or heterogeneous populations due to differing diagnoses necessitating gastrectomy or esophagectomy. As such, this retrospective study was conducted to evaluate the outcome and risk factors of endoscopic therapy for AL in a large cohort, which consisted of consecutive patients who underwent gastrectomy for gastric cancer.

\section{Patients and methods}

\section{Patients}

Between December 2007 and January 2016, 4,916 patients who were diagnosed with gastric cancer underwent gastrectomy at the National Cancer Center, Korea. We reviewed the medical records of these patients, and those who developed AL after gastrectomy were considered for inclusion in this study. Of these patients, those with ALs that were managed conservatively or surgically were excluded so that only patients who underwent endoscopic treatment were included in the final analysis (Fig. 1).

Baseline demographic and clinical characteristics were obtained from a prospectively collected database, including age, sex, body mass index, comorbidities, American Society of Anesthesiologists (ASA) score [22], tumor characteristics, and method of gastrectomy. This study was approved by the Institutional Review Board (IRB) of the National Cancer Center, Korea (IRB approval Number, NCC2016-0229). The requirement for informed consent was waived for all subjects by the IRB because of the low-risk nature of the study.

\section{Surgical procedures for gastrectomy}

All patients underwent total, subtotal, proximal, or pyloruspreserving gastrectomy with lymph node dissection performed by experienced surgeons. The following reconstruction methods were used: Roux-en-Y esophagojejunostomy for total gastrectomy; Billroth I, II, or Roux-en-Y anastomosis for subtotal gastrectomy; esophagogastrostomy for

Fig. 1 Study flows

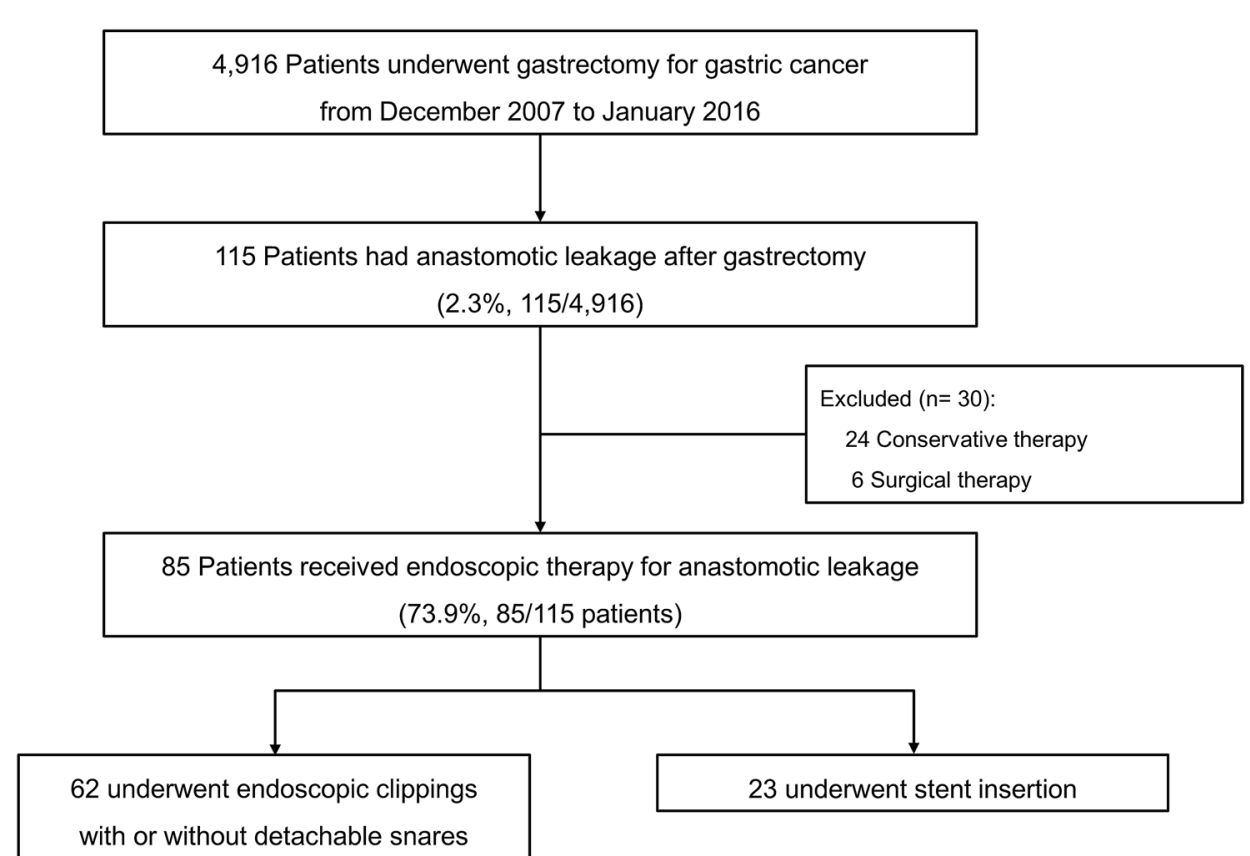


proximal gastrectomy; and gastrogastrostomy for pyloruspreserving gastrectomy. The extent of lymph node dissection was D1 + or D2 according to the Japanese gastric cancer treatment guidelines [23]. All gastrectomies were performed by laparoscopic or open surgery.

\section{Diagnosis of AL after gastrectomy}

After gastrectomy, patients who had clinical presentations suggesting peritonitis and abnormally drained gastrointestinal contents were suspected of having AL. AL was confirmed in these patients if the leakage was confirmed by abdominal computed tomography (CT), fluoroscopy with radiocontrast, or endoscopy.

\section{Endoscopic management of AL}

Endoscopic clippings or stents were used for the management of AL. Experienced endoscopists performed all procedures with a standard upper endoscope (GIF-2T240 or GIF-H260; Olympus, Tokyo, Japan). Endoscopic clippings of small defects were performed using direct closure with multiple hemoclips (EZ Clip ${ }_{\mathrm{TM}}$, HX-610-090L or HX-610-135L; Olympus, Tokyo, Japan). In cases of major defects that could not be closed directly by hemoclips alone, detachable snares were used to approximate the size of the AL (Endo-Loop ${ }_{\mathrm{TM}}$, MAJ-254 or MAJ-340; Olympus,
Tokyo, Japan) after applying hemoclips around the margin of the AL (Fig. 2A).

For patients managed using stents, a modified fully covered self-expandable metal stent (SEMS) (CHOOSTENT $_{\mathrm{TM}}$; M.I.Tech, Suwon, Korea) was applied using Shim's technique as described in a previous study [24]. After placement of the guidewire, the modified fully covered SEMS was implanted across the leakage site under fluoroscopic and endoscopic guidance. Finally, the SEMS was fixed in the appropriate position using a technique similar to that of pulling out a nasobiliary drainage catheter (Fig. 2B).

\section{Follow-up after endoscopic managements and study outcomes}

Follow-up endoscopic examinations were performed every 3 days for patients who underwent endoscopic clippings and every 7 days for those who received a stent. In cases of persistent AL, additional endoscopic therapies were performed at the discretion of the endoscopist, including additional clippings and stent repositioning. After oral administration of radiocontrast, fluoroscopy or CT scans confirmed the complete closure of the AL. The primary outcome of this study was the efficacy of endoscopic management, which was defined as the rate of complete closure. Secondary outcomes were the differences in clinical factors associated with
Fig. 2 Endoscopic management of anastomotic leakage. A Endoscopic clippings with detachable snares were used to achieve primary closure for duodenal stump leakage after subtotal gastrectomy with Billroth II anastomosis (arrows). B Endoscopic stent insertion using Shim's technique was performed to treat anastomotic leakage at the esophagojejunostomy site after total gastrectomy (arrows)
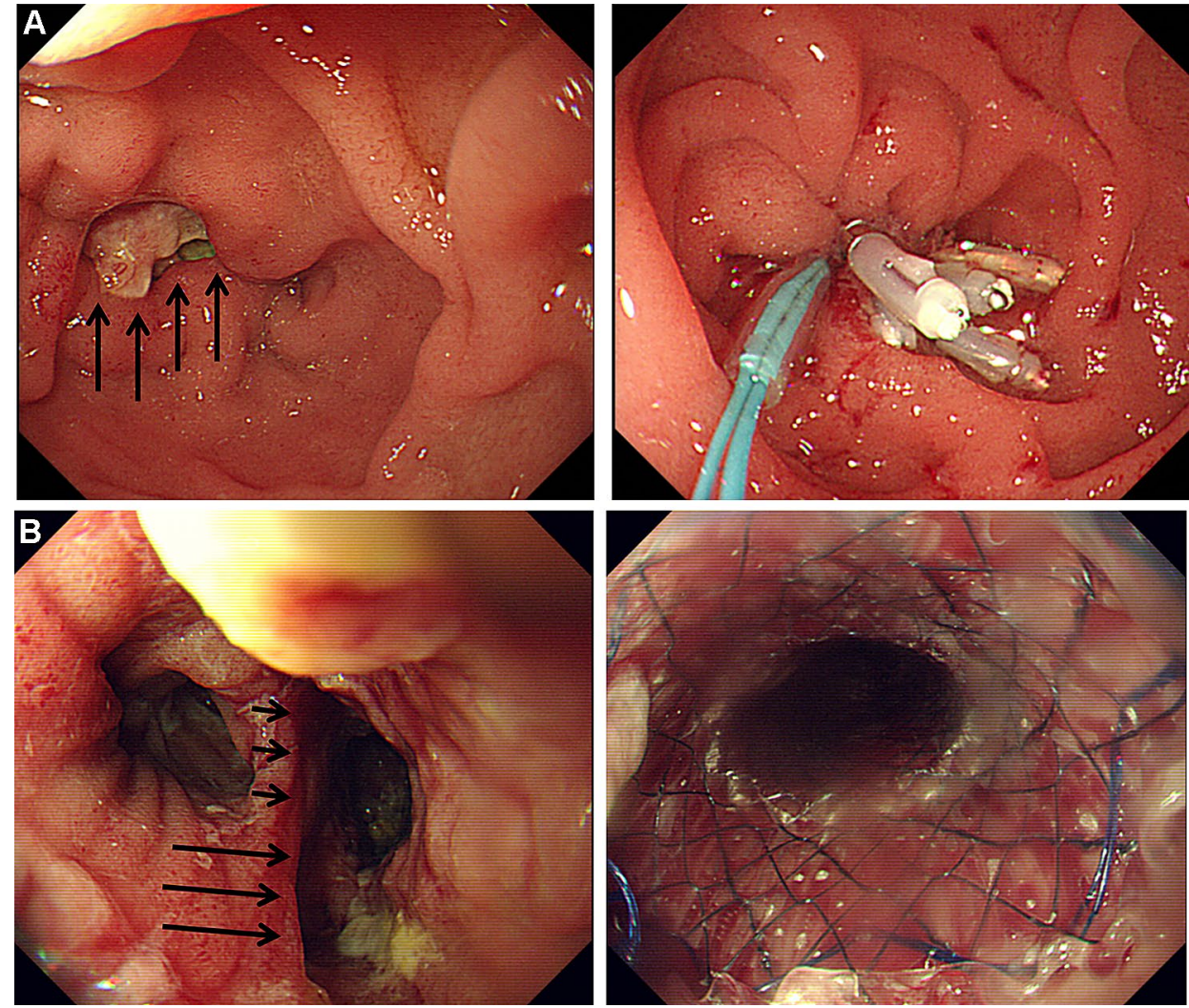
successful AL closure between the two methods of endoscopic management.

\section{Statistical analysis}

The two endoscopic management groups were compared using the Chi-squared test or Fisher's exact test for categorical variables and the Mann-Whitney $U$ test for non-categorical variables. Factors associated with complete leakage closure were investigate using univariate logistic regression analyses. Covariates that were statistically significant in the univariate analyses were included in a multivariate logistic regression analysis. A $P$ value of less than 0.05 was considered to be statistically significant. Data were analyzed using Stata 16.0 (StataCorp, College Station, TX, USA).

\section{Results}

\section{Baseline characteristics}

A total of 115 gastric cancer patients $(2.3 \%, 115 / 4,916$ patients) developed AL after gastrectomy between December 2007 and January 2016 (Fig. 1). Of these, 30 patients who received a conservative therapy or surgical therapy were excluded. Conservative therapy was performed in 24 clinically stable patients with AL only evident on abdominal CT scan. Six patients received surgical therapy because they had another severe condition including severe septic condition $(n=3)$, uncontrolled intra-abdominal bleeding $(n=2)$, and diffuse ischemic change of gastric wall $(n=1)$. Finally, the remaining 85 patients who received endoscopic therapy for AL (62 received endoscopic clippings with or without detachable snares [clipping group] and 23 received stents [stent group]) were included. The baseline clinical characteristics of the patients are presented in Table 1. Median age of the included patients was 63 years, and the proportion of male patients was $77.7 \%$.

Compared with the clipping group, the stent group was older $(P=0.038)$, had a higher proportion of advanced gastric cancer $(P=0.014)$, had longer surgery time $(P=0.042)$, and included more patients who underwent total gastrectomy $(P=0.038)$, open gastrectomy $(P=0.011)$, and Roux-en-Y anastomosis $(P=0.004)$. There were no significant differences in other baseline clinical characteristics, including sex, body mass index, comorbidities, ASA scores, tumor location, and stage.

\section{Characteristics of AL according to endoscopic management (Table 2)}

AL was most commonly diagnosed using an abdominal CT examination (69.4\%). The median time between gastrectomy and AL diagnosis was 8 days (interquartile range [IQR], 6-13 days), and no difference was found regarding this timeframe between the clipping group and stent group (median time, 9 days vs. 7 days; $P=0.062$ ). The leakage size was significantly smaller in the clipping group than the stent group (mean leakage size, $8.9 \mathrm{~mm}$ vs. $18.7 \mathrm{~mm}$; $P<0.001)$. AL sites were different between the treatment groups $(P=0.006)$. Stent insertions were mostly performed for esophagojejunostomy or esophagogastrostomy AL sites (78.3\%), whereas endoscopic clippings with or without detachable snares were performed with similar proportions for esophagojejunostomy or esophagogastrostomy (40.3\%) and duodenal or jejunal stump leakage sites (37.1\%).

\section{Outcomes of endoscopic management}

The time between AL diagnosis and beginning of endoscopic therapy was longer in the stent group (median 10 days [IQR, 7-22 days]) than in the clipping group (median 5 days [IQR, $0-12$ days]; $P=0.01$ ). The overall complete closure rate of AL by endoscopic therapy was $80 \%$, and there was no significant difference in the complete closure rate between the clipping group and stent group $(79.0 \%$ vs. $82.6 \% ; P=0.89$; Table 3). The time from the beginning of endoscopic therapy to complete closure of the AL was significantly longer in the stent group than the clipping group (median time, 26 days vs. 13 days, respectively; $P<0.001$ ). The groups showed no difference in the total number of endoscopic therapy sessions and the presence of intra-abdominal abscess treated by percutaneous drainage. Because of incomplete leakage closure by the first session of endoscopic therapy, 33 patients (28 in the clipping group and 5 in the stent group) underwent two or more sessions of endoscopic therapies. The clipping group had more patients who needed endoscopic therapy sessions $\geq 2$ times than the stent group ( $45.2 \%$ vs. $21.7 \%$; $P=0.049$ ).

The complete leakage closure rates were $86.1 \%$ (37/43 patients) for esophagojejunostomy or esophagogastrostomy sites, $94.1 \%$ (16/17 patients) for gastroduodenostomy, gastrojejunostomy, or gastrogastrostomy sites, and $60.0 \%$ (15/25 patients) for duodenal or jejunal stump sites (Fig. 3). In patients with stump site leakages, duodenal stump leakage was detected in 18 patients and jejunal stump in 7 patients. All patients with duodenal stump leakage underwent endoscopic clippings with or without detachable snares, and 12 patients (66.7\%, 12/ 18 patients) achieved complete leakage closure. The remaining 6 patients had partial leakage closure, and achieved complete leakage closure after additional conservative treatment. For patients with jejunal stump leakage, stent insertion was performed in 3 patients and endoscopic clippings with or without detachable snares in 4 patients. Only 3 patients ( $42.9 \%, 3 / 7$ patients) achieved complete leakage closure. The rate of complete leakage 
Table 1 Baseline clinical characteristics

\begin{tabular}{|c|c|c|c|c|}
\hline \multirow[t]{2}{*}{ Characteristics } & \multirow{2}{*}{$\begin{array}{l}\text { Total } \\
N=85\end{array}$} & \multicolumn{2}{|c|}{ Endoscopic therapy } & \multirow[t]{2}{*}{$P$ value } \\
\hline & & $\begin{array}{l}\text { Clips } \pm \text { snare } \\
N=62\end{array}$ & $\begin{array}{l}\text { Stent } \\
N=23\end{array}$ & \\
\hline Age (years), median (IQR) & $63(52-71)$ & $61(49-70)$ & $67(59-73)$ & 0.038 \\
\hline Sex, $n(\%):$ & & & & 0.504 \\
\hline Male & $66(77.7)$ & $47(75.8)$ & $19(82.6)$ & \\
\hline Female & $19(22.4)$ & $15(24.2)$ & $4(17.4)$ & \\
\hline BMI $\left(\mathrm{kg} / \mathrm{m}^{2}\right)$, mean $\pm \mathrm{SD}$ & $24.3 \pm 2.7$ & $24.2 \pm 2.6$ & $24.7 \pm 3.1$ & 0.232 \\
\hline Comorbidity $^{\mathrm{a}}, n(\%)$ & $45(52.9)$ & $30(48.4)$ & $15(65.2)$ & 0.167 \\
\hline ASA score, $n(\%)$ & & & & 0.628 \\
\hline 1 & $22(25.9)$ & $15(24.2)$ & $7(30.4)$ & \\
\hline 2 & $59(69.4)$ & $43(69.4)$ & $16(69.6)$ & \\
\hline 3 & $4(4.7)$ & $4(6.5)$ & $0(0)$ & \\
\hline Cancer type, $n(\%)$ & & & & 0.014 \\
\hline EGC & $48(56.5)$ & $40(64.5)$ & $8(34.8)$ & \\
\hline AGC & $37(43.5)$ & $22(35.5)$ & $15(65.2)$ & \\
\hline Tumor location, $n(\%)$ & & & & 0.242 \\
\hline Upper & $32(37.7)$ & $20(32.3)$ & $12(52.2)$ & \\
\hline Middle & $25(29.4)$ & $19(30.7)$ & $6(26.1)$ & \\
\hline Lower & $28(32.9)$ & $23(37.1)$ & $5(21.7)$ & \\
\hline Tumor stage $^{\mathrm{b}}, n(\%)$ & & & & 0.075 \\
\hline I & $52(61.2)$ & $42(67.7)$ & $10(43.5)$ & \\
\hline II & $14(16.5)$ & $8(12.9)$ & $6(26.1)$ & \\
\hline III & $18(21.2)$ & $12(19.4)$ & $6(26.1)$ & \\
\hline IV & $1(1.2)$ & $0(0)$ & $1(4.4)$ & \\
\hline Operation time (minutes), mean $\pm \mathrm{SD}$ & $222.5 \pm 80.3$ & $213.4 \pm 73.9$ & $247.1 \pm 92.8$ & 0.042 \\
\hline Type of gastrectomy, $n(\%)$ & & & & 0.038 \\
\hline Total & $41(48.2)$ & $24(38.7)$ & $17(73.9)$ & \\
\hline Subtotal & $34(40.0)$ & $29(46.8)$ & $5(21.7)$ & \\
\hline Proximal & $3(3.5)$ & $3(4.8)$ & $0(0)$ & \\
\hline PPG & $7(8.2)$ & $6(9.7)$ & $1(4.4)$ & \\
\hline Reconstruction method, $n(\%)$ & & & & 0.004 \\
\hline Billroth I & $13(15.3)$ & $10(16.1)$ & $3(13.0)$ & \\
\hline Billroth II & $20(23.5)$ & $19(30.7)$ & $1(4.4)$ & \\
\hline Roux-en-Y & $45(52.9)$ & $26(41.9)$ & $19(82.6)$ & \\
\hline Others $^{c}$ & $7(8.2)$ & $7(11.3)$ & $0(0)$ & \\
\hline Mode of surgery, $n(\%)$ & & & & 0.011 \\
\hline Laparoscopy & $45(52.9)$ & $38(61.3)$ & $7(30.4)$ & \\
\hline Open & $40(47.1)$ & 24 (38.7) & $16(69.6)$ & \\
\hline
\end{tabular}

$A S A$ American society of anesthesiologists, $B M I$ body mass index, $I Q R$ interquartile range, $P P G$ pyloruspreserving gastrectomy, $S D$ standard deviation

${ }^{a}$ Comorbidity included hypertension, diabetes mellitus, cardiac arrhythmia, ischemic heart disease, and liver cirrhosis

${ }^{\mathrm{b}}$ The $7^{\text {th }}$ edition of the International Union Against Cancer/American Joint Committee on Cancer TNM classification system was used for gastric cancer staging

${ }^{\mathrm{c} O t h e r}$ anastomosis methods included esophagogastrostomy and gastrogastrostomy closure was significantly lower for duodenal and jejunal stump sites than the other leakage sites $(P=0.026)$. However, no statistical significance was found in the differences in complete leakage closure rates between the clipping group and stent group at each leakage site. All 14 patients with partial AL closure by endoscopic therapy achieved complete closure after conservative management, including antibiotics and prolonged fasting. Of 3 patients with AL closure 
Table 2 Comparisons of anastomotic leakage characteristics according to modalities of endoscopic therapy

\begin{tabular}{|c|c|c|c|}
\hline \multirow[t]{2}{*}{ Characteristics } & \multicolumn{2}{|c|}{ Endoscopic therapy } & \multirow[t]{2}{*}{$P$ value } \\
\hline & $\begin{array}{l}\text { Clips } \pm \text { snare } \\
N=62\end{array}$ & $\begin{array}{l}\text { Stent } \\
N=23\end{array}$ & \\
\hline Diagnostic method of leakage, $n(\%)$ & & & 0.905 \\
\hline Endoscopy & $17(27.4)$ & $5(21.7)$ & \\
\hline Abdomen CT & $42(67.7)$ & $17(73.9)$ & \\
\hline Fluoroscopy & $3(4.8)$ & $1(4.4)$ & \\
\hline Time between surgery and leakage diagnosis (days), median (IQR) & $9(7-16)$ & $7(5-9)$ & 0.062 \\
\hline Leakage size $(\mathrm{mm})$, mean \pm SD & $8.9 \pm 7.3$ & $18.7 \pm 9.8$ & $<0.001$ \\
\hline Leakage site, $n(\%)$ & & & 0.006 \\
\hline Esophagojejunostomy or esophagogastrostomy site & $25(40.3)$ & $18(78.3)$ & \\
\hline Gastroduodenostomy, gastrojejunostomy, or gastrogastrostomy site & $14(22.6)$ & $3(13.0)$ & \\
\hline Duodenal stump or jejunal stump site & $23(37.1)$ & $2(8.7)$ & \\
\hline
\end{tabular}

$C T$ computed tomography, IQR interquartile range, $S D$ standard deviation

\begin{tabular}{|c|c|c|c|}
\hline \multirow[t]{2}{*}{ Characteristics } & \multicolumn{2}{|c|}{ Endoscopic therapy } & \multirow[t]{2}{*}{$P$ value } \\
\hline & $\begin{array}{l}\text { Clips } \pm \text { snare } \\
N=62\end{array}$ & $\begin{array}{l}\text { Stent } \\
N=23\end{array}$ & \\
\hline $\begin{array}{l}\text { Time from leakage diagnosis to beginning of endo- } \\
\text { scopic therapy (days), median (IQR) }\end{array}$ & $5(0-12)$ & $10(7-22)$ & 0.01 \\
\hline Combination of endoscopic therapy, $n(\%)$ & & & 0.023 \\
\hline No & $60(96.8)$ & $19(82.6)$ & \\
\hline Yes & $2(3.2)$ & $4(17.4)$ & \\
\hline Endoscopic therapy session, no (range) & $1(1-11)$ & $1(1-9)$ & 0.069 \\
\hline Endoscopic therapy session $\geq 2$ times, no (\%) & $28(45.2)$ & $5(21.7)$ & 0.049 \\
\hline Intra-abdominal abscess, $n(\%)$ & & & 0.931 \\
\hline Absent & $29(46.8)$ & $11(47.8)$ & \\
\hline Present & $33(53.2)$ & $12(52.2)$ & \\
\hline Endoscopic therapy result, $n(\%)$ & & & 0.89 \\
\hline Successful complete closure & $49(79.0)$ & $19(82.6)$ & \\
\hline Partial closure & $11(17.7)$ & $3(13.0)$ & \\
\hline Failed closure & $2(3.2)$ & $1(4.4)$ & \\
\hline $\begin{array}{l}\text { Time from beginning of endoscopic therapy and } \\
\text { complete closure of leakage (days), median (IQR) }\end{array}$ & $13(7-24)$ & $26(18-41)$ & $<0.001$ \\
\hline
\end{tabular}

$I Q R$ interquartile range
Table 3 Outcomes of endoscopic therapy for anastomotic leakage failure, 2 patients $(2.4 \%)$ died 2 months after gastrectomy, and 1 patient achieved complete closure after undergoing a reoperation.

\section{Factors associated with failure of complete AL closure by endoscopic therapy}

Duodenal or jejunal stump leakage (crude odd ratio [cOR], $4.11 ; P=0.019)$ and the presence of intra-abdominal abscess (cOR, 5.57; $P=0.012$ ) were significantly associated with the failure of complete AL closure in univariate analyses (Table 4). The multivariate analysis showed that independent factors linked to AL closure failure by endoscopic therapy were duodenal or jejunal stump leakage (adjusted OR [aOR], $4.51 ; P=0.031)$ and the presence of intra-abdominal abscess (aOR, 4.92; $P=0.025$ ). However, the endoscopic modality was not an independent factor associated with unsuccessful AL closures (aOR for stent insertion, 1.38; $P=0.672$ ).

\section{Discussion}

Previous studies investigating the efficacy of endoscopic management of AL after upper gastrointestinal surgery were limited by small case numbers (fewer than 30) [17-21] and heterogeneous groups of patients who underwent surgery 


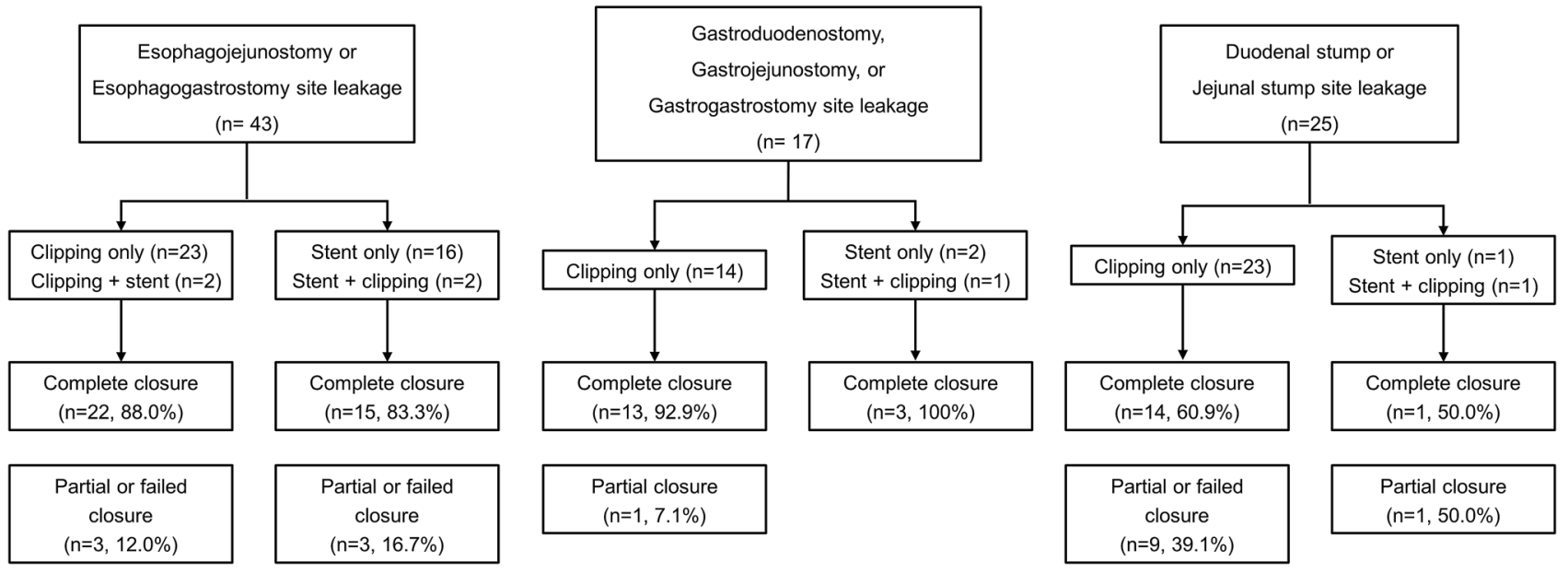

Fig. 3 Outcomes of endoscopic therapy according to anastomotic leakage sites after gastrectomy

due to differing diagnoses [19, 20]. In this study, we reported the efficacy of endoscopic therapy for a large number of consecutive gastric cancer patients who developed AL after gastrectomy. The rate of complete AL closure by endoscopic therapy was $80 \%$, and endoscopic clippings with or without snares showed comparable success rates of complete leakage closure to that of stent insertion. Duodenal or jejunal stump leakage and the presence of intra-abdominal abscess were associated with incomplete AL closure by endoscopic therapy.

Two recent studies reported therapeutic outcomes comparing two endoscopic therapies for AL after gastrectomy for gastric cancer patients $[17,18]$. In a study by Shim et al. [18], stent insertion using SEMS showed a significantly higher success rate of AL sealing after one attempt than endoscopic clippings with or without a detachable snare ( $80.0 \%$ vs. $28.6 \%$, respectively). There was no difference in the success rate regarding multiple endoscopic sessions between the two endoscopic therapies $(80.0 \%$ for stent insertion vs. $64.3 \%$ for clippings; $P=0.653$ ). However, this study was limited by its small case size (only 27 patients who had esophagojejunostomy AL after gastrectomy were included). Another study reported a relatively high success rate of endoscopic clippings to treat AL after total or subtotal gastrectomy in 20 gastric cancer patients [19]. This study was also limited by its small case size.

Reported success rates of endoscopic therapy for AL in patients who underwent gastrectomy are between 59 and 95\% [17-19]. However, these studies did not compare the outcomes of different AL sites. In the present study, the total success rate of complete AL closure was $80 \%$, which is similar to previous studies. Success rates also varied among different AL sites, with duodenal or jejunal stump leakage showing a lower complete closure rate $(60 \%)$ than ALs of the esophagus (86\%) and stomach (94\%). Moreover, stump leakage was an independent factor associated with the failure of endoscopic therapy for AL. The lower success rate of endoscopic therapy for stump leakages may be due to the difficulty of approaching this region using endoscopy as a result of access issues such as limited space and stump opening angulation.

Moreover, the characteristics of the AL site affected the type of endoscopic therapy selected in this study. Endoscopic clippings with or without detachable snares were used more frequently for AL at stomach and stump sites than stents. Regarding AL sites of the stomach, as in the case of gastrojejunostomy or gastrogastrostomy, stent insertion appeared to be ineffective for two main reasons: the anastomotic lumen was so large that the stent could not fully cover the leakage site, or the stent readily migrated from the placed site.

In addition, stent insertion was generally not performed for stump leakages because these locations did not have suitable anatomy for stent placement. However, stent insertion was used more frequently for cases of large esophageal AL because of easier technical access and a smaller number of endoscopic therapy sessions than clippings, as shown in a previous study [18]. These findings suggest that delivering tailored endoscopic therapy according to the leakage site characteristics may be needed to achieve better outcomes.

Surgical correction with primary closure was considered for duodenal stump leakages, but reoperation was not recommended due to its high mortality risk of 20 to $28 \%$ [11-13]. Thus, the least invasive method of treatment was performed to manage duodenal stump leakage, including conservative treatment $[11,12]$, percutaneous drainage [12, 25], or endoscopic therapy [26, 27]. Despite encouraging preliminary evidence describing the efficacy of the endoscopic treatment of $\mathrm{AL}$, the outcomes have not been investigated adequately, and only a case report has been published. In the present 
Table 4 Factors associated with failure of complete closure of anastomotic leakage by endoscopic therapy

\begin{tabular}{|c|c|c|c|c|c|c|}
\hline \multirow[t]{2}{*}{ Factor } & \multicolumn{3}{|c|}{ Univariate analysis } & \multicolumn{3}{|c|}{ Multivariate analysis } \\
\hline & $\mathrm{cOR}$ & $95 \% \mathrm{CI}$ & $P$ value & $\mathrm{aOR}$ & $95 \% \mathrm{CI}$ & $P$ value \\
\hline \multicolumn{7}{|l|}{ Age } \\
\hline$\leq 65$ years & 1.00 & & & & & \\
\hline$>65$ years & 1.00 & $0.34-2.94$ & $>0.99$ & & & \\
\hline \multicolumn{7}{|l|}{ Sex } \\
\hline Male & 1.00 & & & & & \\
\hline Female & 1.09 & $0.31-3.83$ & 0.896 & & & \\
\hline \multicolumn{7}{|l|}{ Body mass index } \\
\hline$\leq 25 \mathrm{~kg} / \mathrm{m}^{2}$ & 1.00 & & & & & \\
\hline$>25 \mathrm{~kg} / \mathrm{m}^{2}$ & 0.94 & $0.31-2.85$ & 0.91 & & & \\
\hline \multicolumn{7}{|l|}{ Comorbidity } \\
\hline Absence & 1.00 & & & & & \\
\hline Presence & 1.00 & $0.34-2.90$ & $>0.99$ & & & \\
\hline \multicolumn{7}{|l|}{ Tumor stage } \\
\hline Stage I & 1.00 & & & & & \\
\hline Stage $\geq$ II & 0.83 & $0.27-2.51$ & 0.739 & & & \\
\hline \multicolumn{7}{|l|}{ Mode of surgery } \\
\hline Laparoscopy & 1.00 & & & & & \\
\hline Open & 1.00 & $0.34-2.90$ & $>0.99$ & & & \\
\hline Surgery time (minutes) & 0.99 & $0.99-1.00$ & 0.243 & & & \\
\hline Days between surgery and leakage diagnosis & 0.95 & $0.87-1.03$ & 0.215 & & & \\
\hline \multicolumn{7}{|l|}{ Leakage site } \\
\hline Esophagojejunostomy or esophagogastrostomy site & 1.00 & & & 1.00 & & \\
\hline $\begin{array}{l}\text { Gastroduodenostomy, gastrojejunostomy, gastrogastrostomy, or } \\
\text { wedge resection site }\end{array}$ & 0.39 & $0.04-3.47$ & 0.395 & 0.53 & $0.05-5.21$ & 0.587 \\
\hline Duodenal stump or jejunal stump site & 4.11 & $1.27-13.33$ & 0.019 & 4.51 & $1.15-17.68$ & 0.031 \\
\hline \multicolumn{7}{|l|}{ Leakage size } \\
\hline$\leq 10 \mathrm{~mm}$ & 1.00 & & & & & \\
\hline$>10 \mathrm{~mm}$ & 1.00 & $0.33-3.04$ & $>0.99$ & & & \\
\hline \multicolumn{7}{|l|}{ Intra-abdominal abscess } \\
\hline Absent & 1.00 & & & 1.00 & & \\
\hline Present & 5.57 & $1.47-21.17$ & 0.012 & 4.92 & $1.23-19.72$ & 0.025 \\
\hline Days from leakage diagnosis to beginning of endoscopic therapy & 1.00 & $0.97-1.03$ & 0.92 & & & \\
\hline \multicolumn{7}{|l|}{ Modality of endoscopic therapy } \\
\hline Clips \pm snare & 1.00 & & & & & \\
\hline Stent & 0.79 & $0.23-2.74$ & 0.715 & 1.38 & $0.31-6.07$ & 0.672 \\
\hline
\end{tabular}

$a O R$ adjusted odd ratio; $c O R$ crude odd ratio; $C I$ confidence interval

*Logistic regression analyses were performed

study, stump leakage sites were implicated as an independent risk factor for the failure of complete leakage closure by endoscopic therapy. The success rate of complete closure in this study was relatively high ( $60 \%$ of 25 patients) despite technical and anatomical difficulties hindering the endoscopic approach for stump sites.

Intra-abdominal abscess can occur as a result of AL after gastrectomy and manifests as abdominal pain, fever, and leukocytosis. Furthermore, this complication may cause a delay of complete AL closure. Thus, intravenous antibiotics and external drainage are needed to treat intra-abdominal abscess after gastrectomy. Intra-abdominal abscess occurred in 53\% of AL after gastrectomy in this study and was another significant risk factor for the failure of complete leakage closure by endoscopic therapy. This result suggests that earlier and more intensive interventions should be performed to achieve complete AL closure by endoscopic therapy, especially in patients with intra-abdominal abscess.

Based on our study findings, we suggest a treatment algorithm for the management of AL developing after 


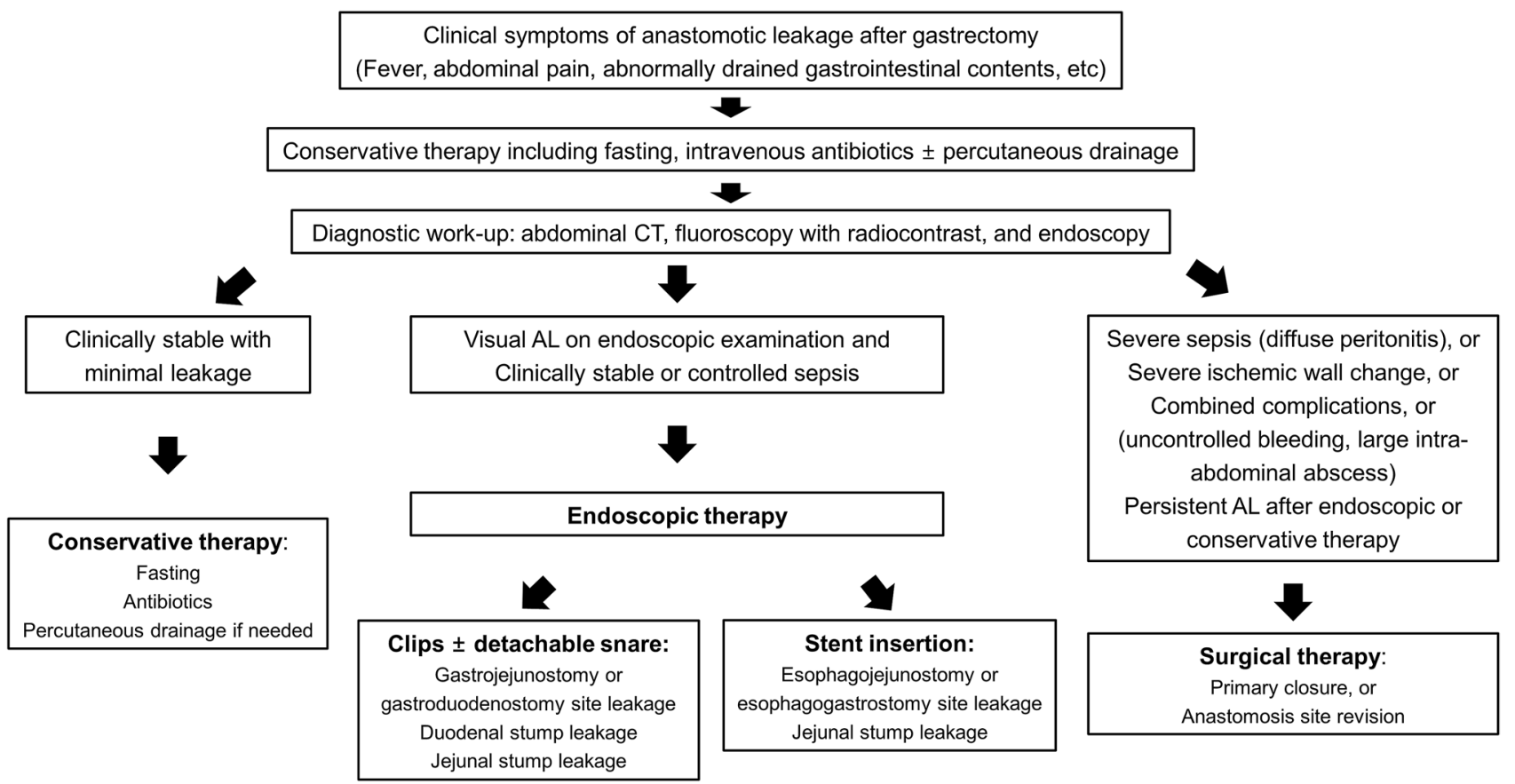

Fig. 4 Suggested treatment algorithm for the management of AL developing after gastrectomy

gastrectomy (Fig. 4). After the diagnostic work-up with abdominal CT scan, fluoroscopy with radiocontrast and endoscopy, the therapy provided is determined according to patient clinical status. Conservative therapy is provided to patients who are clinically stable and had a minimal AL not visible on endoscopic examination. Endoscopic therapy is performed in patients with a visible AL who had controlled sepsis or whose clinical status is stable. Endoscopic therapy modalities are selected according to the AL site. Meanwhile, surgical therapy is performed in patients with following conditions: severe septic condition, severe ischemic wall change, other combined complications requiring surgical treatment including uncontrolled bleeding or large intraabdominal abscess, or persistent AL after conservative or endoscopic therapy.

The strengths of this study include its large cohort size and outcome analysis based on the stratification of different AL sites, especially for stump leakage sites. However, it has several limitations. First, this study was retrospectively conducted with patient data from a single institution. Second, the choice of endoscopic technique (clippings vs. stents) was at the discretion of the endoscopist. In addition, therapeutic options of AL (conservative vs. endoscopic vs. surgical) were determined according to patients' clinical status and extent of AL. These may have resulted in selection bias.

In conclusion, the results of this study strongly indicate that endoscopic therapy is effective for the treatment of AL post-gastrectomy in gastric cancer patients. Therefore, it may be considered as a primary treatment option in treating ALs after gastrectomy in gastric cancer patients.

Acknowledgements This work was supported by grants NCC1410130, NCC-1710120, and NCC-2010090 from the National Cancer Center, Korea.

Author contributions Study conceptions and design: YWK, JYL, acquisition of data: All authors, analysis and interpretation of data: YWK, YIK, JYL, drafting of the manuscript: YWK, YIK, JYL, KH and critical revision of the manuscript: all authors.

Funding This work was supported by Grants NCC-1410130, NCC1710120, and NCC-2010090 from the National Cancer Center, Korea.

\section{Declarations}

Disclosure Drs. Young-Il Kim, Jong Yeul Lee, Harbi Khalayleh, Chan Gyoo Kim, Hong Man Yoon, Soo Jin Kim, Hannah Yang, Keun Won Ryu, Il Ju Choi, Young-Woo Kim have no conflicts of interest or financial ties to disclose.

Ethical approval This study was approved by the Institutional Review Board of the National Cancer Center. Date of approval 28.09.2016.

Informed consent The IRB waived the need for informed consent for this retrospective study (IRB. No.NCC2016-0229).

Open Access This article is licensed under a Creative Commons Attribution 4.0 International License, which permits use, sharing, adaptation, distribution and reproduction in any medium or format, as long as you give appropriate credit to the original author(s) and the source, 
provide a link to the Creative Commons licence, and indicate if changes were made. The images or other third party material in this article are included in the article's Creative Commons licence, unless indicated otherwise in a credit line to the material. If material is not included in the article's Creative Commons licence and your intended use is not permitted by statutory regulation or exceeds the permitted use, you will need to obtain permission directly from the copyright holder. To view a copy of this licence, visit http://creativecommons.org/licenses/by/4.0/.

\section{References}

1. Bray F, Ferlay J, Soerjomataram I, Siegel RL, Torre LA, Jemal A (2018) Global cancer statistics 2018: GLOBOCAN estimates of incidence and mortality worldwide for 36 cancers in 185 countries. CA Cancer J Clin 68:394-424

2. Kim YG, Kong SH, Oh SY, Lee KG, Suh YS, Yang JY, Choi J, Kim SG, Kim JS, Kim WH, Lee HJ, Yang HK (2014) Effects of screening on gastric cancer management: comparative analysis of the results in 2006 and in 2011. J Gastric Cancer 14:129-134

3. Katanoda K, Matsuda T, Matsuda A, Shibata A, Nishino Y, Fujita M, Soda M, Ioka A, Sobue T, Nishimoto H (2013) An updated report of the trends in cancer incidence and mortality in Japan. Jpn J Clin Oncol 43:492-507

4. Chadi SA, Fingerhut A, Berho M, DeMeester SR, Fleshman JW, Hyman NH, Margolin DA, Martz JE, McLemore EC, Molena D, Newman MI, Rafferty JF, Safar B, Senagore AJ, Zmora O, Wexner SD (2016) Emerging trends in the etiology, prevention, and treatment of gastrointestinal anastomotic leakage. J Gastrointest Surg 20:2035-2051

5. Kim HH, Hyung WJ, Cho GS, Kim MC, Han SU, Kim W, Ryu SW, Lee HJ, Song KY (2010) Morbidity and mortality of laparoscopic gastrectomy versus open gastrectomy for gastric cancer: an interim report-a phase III multicenter, prospective, randomized Trial (KLASS Trial). Ann Surg 251:417-420

6. Eom BW, Kim YW, Lee SE, Ryu KW, Lee JH, Yoon HM, Cho SJ, Kook MC, Kim SJ (2012) Survival and surgical outcomes after laparoscopy-assisted total gastrectomy for gastric cancer: case-control study. Surg Endosc 26:3273-3281

7. Sierzega M, Kolodziejczyk P, Kulig J (2010) Impact of anastomotic leakage on long-term survival after total gastrectomy for carcinoma of the stomach. Br J Surg 97:1035-1042

8. Yoo HM, Lee HH, Shim JH, Jeon HM, Park CH, Song KY (2011) Negative impact of leakage on survival of patients undergoing curative resection for advanced gastric cancer. J Surg Oncol 104:734-740

9. Lang H, Piso P, Stukenborg C, Raab R, Jähne J (2000) Management and results of proximal anastomotic leaks in a series of 1114 total gastrectomies for gastric carcinoma. Eur J Surg Oncol 26:168-171

10. Pickleman J, Watson W, Cunningham J, Fisher SG, Gamelli R (1999) The failed gastrointestinal anastomosis: an inevitable catastrophe? J Am Coll Surg 188:473-482

11. Kim KH, Kim MC, Jung GJ (2014) Risk factors for duodenal stump leakage after gastrectomy for gastric cancer and management technique of stump leakage. Hepatogastroenterology 61:1446-1453

12. Orsenigo E, Bissolati M, Socci C, Chiari D, Muffatti F, Nifosi J, Staudacher C (2014) Duodenal stump fistula after gastric surgery for malignancies: a retrospective analysis of risk factors in a single centre experience. Gastric Cancer 17:733-744

13. Cozzaglio L, Giovenzana M, Biffi R, Cobianchi L, Coniglio A, Framarini M, Gerard L, Gianotti L, Marchet A, Mazzaferro V, Morgagni P, Orsenigo E, Rausei S, Romano F, Rosa F, Rosati R, Roviello F, Sacchi M, Morenghi E, Quagliuolo V (2016) Surgical management of duodenal stump fistula after elective gastrectomy for malignancy: an Italian retrospective multicenter study. Gastric Cancer 19:273-279

14. Marinatou A, Theodoropoulos GE, Karanika S, Karantanos T, Siakavellas S, Spyropoulos BG, Toutouzas K, Zografos G (2014) Do anastomotic leaks impair postoperative health-related quality of life after rectal cancer surgery? A case-matched study. Dis Colon Rectum 57:158-166

15. Turrentine FE, Denlinger CE, Simpson VB, Garwood RA, Guerlain S, Agrawal A, Friel CM, LaPar DJ, Stukenborg GJ, Jones RS (2015) Morbidity, mortality, cost, and survival estimates of gastrointestinal anastomotic leaks. J Am Coll Surg 220(2):195-206

16. Messager M, Warlaumont M, Renaud F, Marin H, Branche J, Piessen G, Mariette C (2017) Recent improvements in the management of esophageal anastomotic leak after surgery for cancer. Eur J Surg Oncol 43:258-269

17. Hoeppner J, Kulemann B, Seifert G, Marjanovic G, Fischer A, Hopt UT, Richter-Scharg HJ (2014) Covered self-expanding stent treatment for anastomotic leakage: outcomes in esophagogastric and esophagojejunal anastomoses. Surg Endosc 28:1703-1711

18. Shim CN, Kim HI, Hyung WJ, Noh SH, Song MK, Kang DR, Park JC, Lee H, Shin SK, Lee YC, Lee SK (2014) Self-expanding metal stents or nonstent endoscopic therapy: which is better for anastomotic leaks after total gastrectomy? Surg Endosc 28:833-840

19. Lee S, Ahn JY, Jung HY, Lee JH, Choi KS, Kim DH, Choi KD, Song HJ, Lee GH, Kim JH, Kim BS, Yook JH, Oh ST, Kim BS, Han S (2013) Clinical outcomes of endoscopic and surgical management for postoperative upper gastrointestinal leakage. Surg Endosc 27:4232-4240

20. Haito-Chavez Y, Law JK, Kratt T, Arezzo A, Verra M, Morino M, Sharaiha RZ, Poley JW, Kahaleh M, Thompson CC, Ryan MB, Choksi N, Elmunzer BJ, Gosain S, Goldberg EM, Modayil RJ, Stavropoulos SN, Schembre DB, DiMaio CJ, Chandrasekhara V, Hasan MK, Varadarajulu S, Hawes R, Gomez V, Wooward TA, Rubel-Cohen S, Fluxa F, Vleggaar FP, Akshintala VS, Raju GS, Khashab MA (2014) International multicenter experience with an over-the-scope clipping device for endoscopic management of GI defects (with video). Gastrointest Endosc 80:610-622

21. Oh HJ, Lim CH, Yoon SB, Lee HH, Kim JS, Cho YK, Park JM, Choi MG (2019) Temporary self-expandable metallic stent placement in post-gastrectomy complications. Gastric Cancer 22:231-236

22. Dripps RD (1963) New classification of physical status. Anesthesiology 24:111

23. Japanese Gastric Cancer Association (2017) Japanese gastric cancer treatment guideline 2014 (ver.4). Gastric Cancer 20:1-19

24. Shim CS, Cho YD, Moon JH, Kim JO, Cho JY, Kim YS, Lee JS, Lee MS (2001) Fixation of a modified covered esophageal stent: its clinical usefulness for preventing stent migration. Endoscopy 33:843-848

25. Ali BI, Park CH, Song KY (2016) Outcomes of non-operative treatment for duodenal stump leakage after gastrectomy in patients with gastric cancer. J Gastric Cancer 16:28-33

26. Wong SK, Lam YH, Lau JY, Lee DW, Chan AC, Chung SC (2000) Diagnostic and therapeutic fistuloscopy: an adjuvant management in postoperative fistulas and abscesses after upper gastrointestinal surgery. Endoscopy 32:311-313

27. Lee JY, Ryu KW, Cho SJ, Kim CG, Choi IJ, Kim MJ, Lee JS, kim HB, Lee JH, Kim YW, (2009) Endoscopic clipping of duodenal stump leakage after Billroth II gastrectomy in gastric cancer patient. J Surg Oncol 100:80-81

Publisher's Note Springer Nature remains neutral with regard to jurisdictional claims in published maps and institutional affiliations. 